Research Article

\title{
Exploration of the association between contact history, socio-cultural factors and acute deliberate self-poisoning in North Central province of Sri Lanka: a case-control study
}

Pushpakumara $\mathrm{PHGJ}^{1}$, Chandrakumara $\mathrm{WAJC}^{2}$, Gunasekara $\mathrm{ACM}^{3}$, Agampodi $\mathrm{SB}^{4}$

${ }^{1}$ Department of Family Medicine, Faculty of Medicine and Allied Sciences, Rajarata University of Sri Lanka

${ }^{2}$ Department of Paediatrics, Faculty of Medicine and Allied Sciences, Rajarata University of Sri Lanka

${ }^{3}$ Postgraduate Institute of Medicine, University of Colombo, Sri Lanka

${ }^{4}$ Department of Community Medicine, Faculty of Medicine and Allied Sciences, Rajarata University of Sri Lanka

\begin{abstract}
Background

Knowledge of someone else's suicidal behaviour significantly increased the risk of similar acts. Though Sri Lanka has implemented a national policy and an action plan to prevent suicides and attempted suicides, in 1997, the number of deliberate self-harm (DSH) incidents is increasing. We conducted a case-control study to identify the precipitants and to assess the possible impact of a contact history for acute deliberate self-poisoning (DSP) in view of identifying possible interventions.
\end{abstract}

\section{Materials and Methods}

We interviewed two hundred DSP patients, admitted to the medical wards of Teaching Hospital Anuradhapura (THA), during June - August 2004. Patients were randomly selected from a block of two consecutively admitted consenting DSP patients and an interviewer-administered questionnaire was completed. Age and sex-matched patients, who had no history of attempted suicide, admitted to medical wards of THA were interviewed as controls.

\section{Results}

Majority of DSP occurred among adolescents and young adults. Conflicts within the family and simple conflicts with someone else were the triggers for the majority $(n=123,61.5 \%, 95 \%$ CI 58.1-64.9\%) of DSP. Our study showed that DSP was common among people who had not completed primary education (OR 4.5, 95\% CI 2.5-7.9, $\mathrm{p}<0.0001)$ and having a history of DSH in an immediate family member or spouse (OR 5.7, 95\% CI-2.2-14.7, $\mathrm{p}<0.0001)$.

\section{Conclusions}

DSP behaviour in rural Sri Lanka seems to be a learned response of vulnerable adolescents and young adults to deal with stressful situations. An in-depth exploration of this finding is needed in order to use it as a key factor in the identification of risk groups for DSP prevention.

Keywords: Self-harm, Suicide, Contact history, Family history, Sri Lanka

Copyright: (C) 2019 Pushpakumara PHGJ et al. (c) (i) This is an open-access article distributed under the Creative CommonsAttribution License, which permits unrestricted use, distribution, and reproduction in any medium, provided the original work is properly cited.

Funding: None

Competing interests: None

$\square$ Correspondence: janakatechno@yahoo.com

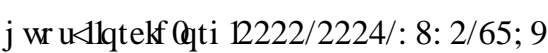

Cite this article as: Pushpakumara PHGJ et al. Exploration of the association between contact history, sociocultural factors and acute deliberate self-poisoning in North Central province of Sri Lanka: a case-control study. Anuradhapura Medical Journal 2019;13 (1):12-17.

DOI: http://doi.org/10.4038/amj.v13i1.7660 


\section{Background}

Deliberate self-harm (DSH) is a global public health issue that is responsible for nearly one million deaths annually (1). Studies showed that people engage in nonfatal suicidal behaviours 10 to 40 times more when compared to suicide $(\underline{2}, \underline{3})$. Rural areas of Sri Lanka have had a persistently high incidence of deliberate selfpoisoning (DSP) since the early 1980s (4-6). Ingestion of poison or taking an overdose of drugs with suicidal intent accounts for more than $80 \%$ of deliberate selfharm in Sri Lanka (7). North Central Province (NCP) is one of the severely affected provinces with annual incidence rates of DSP and fatal self-poisoning being $447(\underline{5})$ and $27(\underline{8})$ per 100,000, respectively, in 2010 and 2002.

Knowledge of someone else's suicidal behaviour significantly increased the risk of similar acts $(\underline{9})$. The rate of suicide attempts and suicidal ideation is high among first-degree relatives (10). Moreover, those who had a family history reported significantly higher levels of impulsivity (11).

Sri Lanka implemented a national policy and an action plan on suicide prevention in 1997. There is a general agreement among researchers and stakeholders that the suicide rate in Sri Lanka is decreasing while the number of DSH is increasing (12-16). Background knowledge concerning the epidemiology of suicide in Sri Lanka is limited despite DSP being an increasingly common response to emotional distress in young adults. The objectives of this study were to explore the association between contact history, socio-cultural factors, and acute DSP in NCP.

\section{Materials and methods}

\section{Study Design and Study Setting}

This case-control study was conducted at Teaching Hospital, Anuradhapura (THA), Sri Lanka. THA is the main referral centre in $\mathrm{NCP}$, which has a capacity of 2092 beds (17), and the majority of acute DSP patients in the NCP are managed in this hospital $(\underline{8}, \underline{18})$.

\section{Procedure}

Two hundred acute DSP patients admitted to the medical wards during June, July, and August 2004, were selected randomly from a block of two consecutively admitted consenting DSP patients as cases. They were interviewed on the day of discharge, and an interviewer- administered questionnaire was completed. The questionnaire consisted of questions to assess the demographic characteristics, educational risk factors, contact history of attempted suicide or suicide within the last 12 months, exposure to stressful life events and circumstances. Age and sex-matched patients, who had no history of attempted suicide, admitted to the medical wards of THA were used as controls. This enabled us to choose the controls from a similar socio-cultural group. Selected determinants of DSP were analyzed using a binary logistic regression model.

\section{Results}

During the selected period, 575 (323[56\%] males and $252[44 \%]$ females) patients were admitted with acute DSP and $29(5 \%, 95 \%$ CI $4.1-5.9 \%)$ of them died. The study sample consisted of $97(48.5 \%)$ males and 103 $(51.5 \%)$ females. Sixty-three $(31.5 \%, 95 \%$ CI $28.2-$ $34.7 \%$ ) of the cases were less than twenty years of age and one third ( $\mathrm{n}=66,33 \%, 95 \%$ CI $29.6-36.3 \%)$ were between 20 and 29 years of age. Control group consisted of participants with same age and sex distribution. Out of the cases, $58(29 \%, 95 \%$ CI $25.8-32.2 \%)$ had not completed their primary education and $102(52.3 \%, 95 \%$ CI $47.5-54.4 \%$ ) were dependents. Majority of the cases $(\mathrm{n}=116,58 \%, 95 \%$ CI $54.5-61.5 \%)$ were never married. Eighty-three $(41.5 \%, 95 \%$ CI $38.0-45.0 \%)$ cases were married and, out of them, three $(1.5 \%, 95 \%$ CI $0.6-$ $2.4 \%$ ) were separated at the time of the event. Previous event(s) of self-harm was reported by $24(12 \%, 95 \% \mathrm{CI}$ $9.7-14.3 \%)$ cases: one previous attempt by $19(9.5 \%$, $95 \%$ CI $7.4-11.6 \%$ ), two previous attempts by three $(1.5 \%, 95 \%$ CI $0.6-2.4 \%)$, three or more previous attempts by one $(0.5 \%, 95 \%$ CI $0.0-1.0 \%)$ patient. Majority of the cases $(\mathrm{n}=80,40.0 \%, 95 \%$ CI 36.5 $43.4 \%)$ were unemployed. Out of the cases, $79(39.5 \%$, $95 \%$ CI $36.0-52.9 \%$ ) were skilled agricultural or fisheries workers, and, $22(11.0 \%, 95 \%$ CI $8.8-13.2 \%)$ were students.

In the present study, the most prominent triggering factor for acute DSP was conflicts within the family ( $\mathrm{n}=73$, $36 \%, 95 \%$ CI $33.1-39.9 \%$ ), the next being the inability to cope with impulsive emotions following a simple conflict with someone else ( $\mathrm{n}=50,25 \%, 95 \%$ CI 21.9 $28.1 \%$ ). Other triggering factors were problems related to love affairs $(\mathrm{n}=26,13 \%, 95 \%$ CI $10.6-15.4 \%)$, economic problems ( $\mathrm{n}=20,10 \%, 95 \%$ CI $7.9-12.1 \%)$, previously diagnosed psychiatric condition $(n=8,4 \%$, $95 \%$ CI $2.6-5.3 \%)$, chronic organic diseases $(n=7$, 
$3.5 \%, 95 \%$ CI $2.2-4.8 \%$ ) and education related problems $(n=3,1.5 \%, 95 \%$ CI $0.6-2.3 \%)$.

The main methods used by subjects for attempted suicide included pesticide ingestion $(\mathrm{n}=105,52.8 \%$, 95\% CI $48.9-56.0 \%$ ) and consumption of yellow oleander (Thevetia peruviana) seeds $(n=53,26.5 \%, 95 \%$ CI 23.4 $-29.6 \%$ ). Overdose of drugs was the chosen method of $11(5.5 \%, 95 \%$ CI $3.9-7.1 \%)$ DSP patients, and a similar number of patients presented with self-ingestion of Kerosene oil. Five $(2.5 \%, 95 \%$ CI $1.4-3.6 \%)$ patients presented with self-ingestion of other biological substances. Seventeen percent of cases $(n=34,95 \%$ CI $14.3-19.7 \%$ ) had a contact history with an immediate family member, including spouse, and $57 \%(\mathrm{n}=114,95 \%$ CI $53.5-60.5 \%$ ) did not have any such contact (Figure1). Out of the male subjects, $47.4 \%(n=46,95 \%$ CI 42.3 $-52.5 \%$ ) were under the influence of alcohol at the time of the incident.

\begin{tabular}{|r|r|}
\hline None & \\
Neighbour/Known & $16(8 \%)$ \\
Friend & $11(5.5 \%)$ \\
Relative & $114(57 \%)$ \\
Spouse & $2(1 \%)$ \\
Sibling & $16(12.5 \%)$ \\
Mother & $7(3.5 \%)$ \\
Father & $9(4.5 \%)$ \\
&
\end{tabular}

Figure 1: Contact history prior to attempted suicide/suicide

The effect of the contact history of DSP among immediate family members, including spouse, on DSP among the study participants, was 5.7 (95\% CI,2.2 14.7, $\mathrm{p}<0.0001)$. Being married showed a 3.8 times higher risk $(95 \%$ CI 2.28-6.61, $\mathrm{p}<0.0001)$ of DSP compared to being unmarried. DSP was common among people who had not completed primary education compared to those with higher educational attainments (OR 4.5, 95\% CI 2.5-7.9, $\mathrm{p}<0.0001$ ). Being unemployed or being a student carried 1.6 times the excess risk (OR $1.6,95 \%$ CI $1.1-2.4, p=0.019$ ) for DSP (Table 1 ).

\section{Discussion}

Most of the DSH occurred among young people, and the incidence peaked in the 21-30 year age group. Similar age distribution patterns were reported by a study conducted in NCP in 2010 (5) and different districts in Sri Lanka. The self-reported recalled lifetime repetition rate of DSH was closer to the reported rates in similar settings.
Table 1: Risk factors for deliberate self-poisoning

\begin{tabular}{|c|c|c|c|c|}
\hline & & Cases & Controls & \multirow{2}{*}{$\begin{array}{c}\text { OR } \\
(95 \% \mathrm{CI}) \\
\mathrm{p}^{* *}\end{array}$} \\
\hline & & $\mathrm{n}(\%, 95 \% \mathrm{CI})$ & $\mathrm{n}(\%, 95 \% \mathrm{CI})$ & \\
\hline \multirow{2}{*}{ Marital Status } & Never Married & $\begin{array}{c}116 \\
(58.0,54.5- \\
61.5)\end{array}$ & $\begin{array}{c}166 \\
(83.0,80.3- \\
85.7)\end{array}$ & \multirow{2}{*}{$\begin{array}{c}3.8 \\
(2.28-6.61) \\
p<0.0001\end{array}$} \\
\hline & Married/Separated & $\begin{array}{c}84 \\
(42.0,38.5- \\
45.5)\end{array}$ & $\begin{array}{c}34 \\
(17.0,14.3- \\
19.7)\end{array}$ & \\
\hline \multirow{2}{*}{$\begin{array}{l}\text { Level of } \\
\text { Education }\end{array}$} & $\begin{array}{l}\text { Primary Education } \\
\text { Not Completed }\end{array}$ & $\begin{array}{c}58 \\
(29.0,25.8- \\
32.2) \\
\end{array}$ & $\begin{array}{c}22 \\
(11.0,8.8- \\
13.2)\end{array}$ & \multirow{2}{*}{$\begin{array}{c}4.5 \\
(2.5-7.99) \\
\mathrm{p}<0.0001\end{array}$} \\
\hline & $\begin{array}{l}\text { Completed Primary } \\
\text { Education }\end{array}$ & $\begin{array}{c}142 \\
(71.0,67.8- \\
74.2) \\
\end{array}$ & $\begin{array}{c}178 \\
(89.0,86.8- \\
91.2)\end{array}$ & \\
\hline \multirow{2}{*}{$\begin{array}{l}\text { Employment } \\
\text { Status }\end{array}$} & Students/Unemployed & $\begin{array}{c}102 \\
(51.0,47.5- \\
54.5) \\
\end{array}$ & $\begin{array}{c}81 \\
(40.5,37.0- \\
43.9) \\
\end{array}$ & \multirow{2}{*}{$\begin{array}{c}1.6 \\
(1.1-2.4) \\
p=0.019\end{array}$} \\
\hline & Employed & $\begin{array}{c}93 \\
(46.5,42.9- \\
50.0) \\
\end{array}$ & $\begin{array}{c}119 \\
(59.5,56.0- \\
62.9) \\
\end{array}$ & \\
\hline \multirow{3}{*}{ Contact History } & $\begin{array}{l}\text { Immediate Family } \\
\text { Member }\end{array}$ & $\begin{array}{c}32 \\
(16.0,13.4- \\
18.6)\end{array}$ & $\begin{array}{c}7 \\
(3.5,2.2-4.8)\end{array}$ & \multirow{3}{*}{$\begin{array}{c}5.7 \\
(2.21-14.7) \\
\mathrm{p}<0.0001\end{array}$} \\
\hline & Others* & $\begin{array}{c}54 \\
(27.0,23.9- \\
30.1) \\
\end{array}$ & $\begin{array}{c}64 \\
(32.0,28.7- \\
35.3) \\
\end{array}$ & \\
\hline & No Contact History* & $\begin{array}{c}114 \\
(57.0,53.5- \\
60.5)\end{array}$ & $\begin{array}{c}129 \\
(64.5,61.1- \\
67.9) \\
\end{array}$ & \\
\hline
\end{tabular}

Several studies conducted in the western part of the world have shown that suicide rates are higher in widowed or divorced people, and there is a protective effect of marriage on suicide (19). However, our study identified marriage as a risk factor. The reason for this difference may be the fact that divorces are less common in the Sri Lankan culture. Conflicts within the family were the most common triggering factor for DSP, and probably they have chosen DSP instead of a divorce. Similar phenomena have been proposed to explain suicide proneness in alcohol use through alcohol-related problems, negative life events, and depressive symptoms. (20). All these factors may explain this finding. Suicidal behaviour is significantly related to having fewer years of formal education. Studies conducted in geographically different and culturally diverse centres reported that a lower level of education was associated with a higher risk for suicidal behaviour (21-23).

Simple conflicts with someone else were the second most common triggering factor for DSP. Some studies also show that the majority of adolescents use DSP as the preferred method of dealing with difficult situations or simply as a way to manipulate a situation to one's own advantage without having a real intention to die (which was not studied in our study) (24). A previous study showed that more than $90 \%$ stated that they knew someone who had harmed themselves, and 90\% knew someone who had killed themselves (25). If knowing someone who has committed suicide is a risk factor for 
deliberate self-harm, all the communities in Sri Lanka are at very high risk $(\underline{26})$. Our study showed that having a contact history of DSH with an immediate family member or spouse increases the DSP risk 5.7 times. Moreover, similar findings were reported by a study conducted in 2013 at socio-economically similar Kurunegala district $(\underline{6}, \underline{27})$.

Based on the observations made on the sociodemographic pattern, triggering factors, contact history of DSP, DSP behaviour in rural Sri Lanka seems to be a learned response of vulnerable adolescents and young adults to deal with stressful situations. This vulnerability may be associated with a low level of education and inadequacy of coping skills necessary to deal with problems $(\underline{28}, \underline{29})$. Screening of immediate family members of DSH for risk factors, socio-economic development of rural communities, and coping skills training may have a positive impact on DSH prevention in rural Sri Lanka. Even though the findings have limited generalizability, in-depth exploration of these findings is important because most of these causes are treatable, and suicides are preventable.

\section{Conclusion}

Having a contact history of DSP and having fewer years of formal education were shown as strong predictors of DSP in the present study. DSP behaviour in rural Sri Lanka seems to be a learned response to deal with daily living challenges. An in-depth exploration of this finding is needed in order to use it as a key factor in the identification of risk groups for DSP prevention.

\section{References}

1. WHO. Suicide: Fact sheets. 2018.

2. De Leo D, Burgis S, Bertolote JMvet al.. Definitions of suicidal behavior: Lessons learned from the WHO/EURO multicentre study. Crisis. 2006;27(1):4 -15.

3. Dietrich S, Wittenburg L, Arensman E et al. Suicide and self-harm. In: Gask L, Lester H, Kendrick T, Peveler R, editors. Primary care mental health. London, UK: The Royal College of Psychiatrists. 2009;138.

4. Knipe DW, Padmanathan P, Muthuwatta L et al. Regional variation in suicide rates in Sri Lanka between 1955 and 2011: a spatial and temporal analysis. BMC Public Health. 2017;17:193.

5. Senarathna L, Jayamanna SF, Kelly PJ et al. Changing epidemiologic patterns of deliberate self-poisoning in a rural district of Sri Lanka. BMC Public Health. 2012;12:593.

6. Pushpakumara PHGJ, Thennakoon S, Rajapakse T et al. A prospective study of repetition of self-harm following deliberate self-poisoning in rural Sri Lanka. PLoS ONE. 2019;14:e0199486.

7. Hanwella R, Senanayake SM, de Silva VA. Geographical variation in admissions due to poisoning in Sri Lanka: a time series analysis. Ceylon Medical Journal. 2012;57(4):152-158.

8. Eddleston M, Sudarshan K, Senthilkumaran M et al. Patterns of hospital transfer for self-poisoned patients in rural Sri Lanka: implications for estimating the incidence of self-poisoning in the developing world. Bulletin of the World Health Organization. 2006;84:276-282.

9. De Leo D, Cerin E, Spathonis K et al. Lifetime risk of suicide ideation and attempts in an Australian community: Prevalence, suicidal process, and help-seeking behaviour. Journal of Affective Disorders. 2005; 86:215-224.

10. Brent DA, Bridge J, Johnson BA et al.Suicidal behavior runs in families. A controlled family study of adolescent suicide victims. Archives of General Psychiatry. 1996;53:1145-1152.

11. Roy A. Family history of suicide and impulsivity. Archives of Suicide Research. 2006;10:347-352.

12. de Silva VA, Senanayake SM, Dias P et al.From pesticides to medicinal drugs: time-series analyses of methods of self-harm in Sri Lanka. Bulletin of the World Health Organization. 2012;90: 40-46.

13. Hussain N. Suicide in Sri Lanka Attempts increase while deaths decrease. Daily Mirror. Colombo: Wijeya Newspapers Ltd. 2013. 
14. Jayasinghe NR, Foster JH. Acute poisoning and suicide/deliberate self-harm trends in Sri Lanka: Alcohol a cause for concern-Some further Observations. Asian J Psychiatr. 2010;3:233-234.

15. Mudugamuwa M. Suicides down, attempts up. The Island. Colombo: Upali Newspapers (Pvt) Ltd. 2013.

16. Mudugamuwa M. Suicide attempts increase in Lanka, while teen suicides drop. The Island. Colombo: Upali Newspapers (Pvt) Ltd. 2011

17. Department of Census and Statistics Sri Lanka. Statistical Handbook: Anuradhapura District - Information on Government Hospitals by Divisional Level - 2019 (Table: 8.1);2020.

18. Senarathna L, Adams J, De Silva D et al. Personal and professional challenges in the management of deliberate self-poisoning patients in rural Sri Lanka: a qualitative study of rural hospital doctors' experiences and perceptions. BMC Public Health. 2008;8:373.

19. Roškar S, Podlesek A, Kuzmani M et al. Suicide risk and its relationship to change in marital status. Crisis.2011;32: 24-30.

20. Lamis DA, Malone PS, Jahn DR. Alcohol use and suicide proneness in college students: A proposed model. Mental Health and Substance Use 2014;7:59-72.

21. Kessler RC, Borges G, Walters EE. Prevalence of and risk factors for lifetime suicide attempts in the National Comorbidity Survey. Archives of General Psychiatry. 1999;56:617-626.

22. Kinyanda E, Kizza R, Levin J et al. Adolescent suicidality as seen in rural North-Eastern Uganda: Prevalence and risk factors. Crisis2011;32:43-51.

23. Kulkarni RR, Rao KN, Begum S. Comorbidity of psychiatric and personality disorders in first suicide attempters: A case-control study. Asian Journal of Psychiatry. 2013;6:410-416.

24. Konradsen F, Hoek W, Peiris P. Reaching for the bottle of pesticide-A cry for help. Self-inflicted poisonings in Sri Lanka. Social Science \& Medicine. 2006;62:1710-1719.

25. Eddleston M, Sheriff MHR, Hawton K. Deliberate self-harm in Sri Lanka: an overlooked tragedy in the developing world. British Medical Journal. 1998;317:133-142.

26. Hawton K, Catalan J. Attempted suicide: A practical guide to its nature and management. New York: Oxford University Press. 1987.

27. Pushpakumara PHGJ. Epidemiological pattern and associates of deliberate self-harm in Kurunegala district, Sri Lanka (M.Phil Thesis). Peradeniya, Sri Lanka: Faculty of Medicine, University of Peradeniya. 2017;325 p.

28. Ratnayeke L. Suicide in Sri Lanka. In: Kosky ea, editor. Suicide prevention. New York: Plenum Press. 1998:139.

29. de Silva HJ, Kasturiarachchi N, Seneviratne SL et al. Suicide in Sri Lanka: points to ponder. Ceylon Medical Journal. 2000;45:17-24.

Submit your next manuscript to
Anuradhapura
Medical Journal
http://amj.sljol.info/

